\title{
The Impact of an Outdoor Orientation Program on First-Year Student Perceptions of Life Effectiveness and Campus Integration
}

\author{
Anna H. Lathrop, Timothy S. O'Connell, \& Ryan A. Howard \\ Brock University
}

Although outdoor orientation programs, as a special type of orientation designed to enhance student retention, are relatively commonplace in the United States - we are not aware of any such campuswide initiatives in Canada. Research indicates that outdoor orientation programs impact students in a positive way, enhancing academic success, personal development, and integration into campus life. This exploratory, mixed methods pilot study reports on the results of an investigation that administered three pre and post surveys that measured indicators of "Life Effectiveness," "Sense of Community," and "Sense of Place" on a group of seven, first-year students who participated on a five-day canoeing trip in the wilderness of Algonquin Park, Ontario, Canada. The program, entitled "Brock BaseCamp," exposed students to a curriculum that included networking with student facilitators about campus life, in addition to acquiring technical skills of canoeing and outdoor living. Results indicated that students were positively influenced in all three measures and that the Brock BaseCamp experience enhanced their social integration into campus life.

\section{Introduction}

C anadian universities in the $21^{\text {st }}$ century face the challenges of lower enrolments, enhanced global competition, and the desire to increase and foster diversity. In the province of Ontario, the Higher Education Quality Council of Ontario (HEQCO) has issued a report that indicates the Ontario university system will begin to follow a model of differentiation defined on the basis of structure, type of programs offered, how research and teaching are provided, institutional status, and student composition (Rae, 2005). This model is also hinged to a move toward greater accountability and the development of performance indicators (such as the National Survey of Student Engagement, or NSSE) that determine whether universities are meeting the outcomes expected of them - including student retention. 
One strategy to enhance student success and promote student retention, driven by statistics that indicate that over $20 \%$ of students who enter university fail to complete their degrees (Finnie \& Qiu, 2009), are first-year or pre-term orientation programs (Hollins, 2009). The goals of these orientation programs are to provide information in the form of education and peer network support that will lead to higher levels of academic performance, emotional and social maturity, and a more positive view of the institution. These first-year programs have historically been delivered as classroom-based, theory-oriented courses, seminars and/or support group interventions (Lamothe et al., 1995; Tinto, 1997).

Over the past several decades in the United States, a number of universities have adopted an alternative approach to orientation program deliveryone that includes a wilderness component designed to enhance personal growth (Davis-Berman \& Berman, 1996), positive peer relationships (Gass, Garvey, Sugarman, 2003), academic performance (Oldmixon, 2007), and retention (Wolfe \& Kay, 2011). Barefoot and Koch (2011) report that over $20 \%$ of the 1,300 public and private colleges and universities they surveyed offered pre-term orientation programs with a wilderness or outdoor education component. Interestingly, we are not aware of any such campuswide wilderness orientation programs for first-year students in Canadian universities or colleges.

This exploratory pilot study was designed to assess the impact of one such outdoor orientation program, entitled Brock BaseCamp, on students' personal development and their integration into university life. The program was initiated at Brock University, St. Catharines, Ontario - a medium sized university (with 17,000 full-time students) located atop the Niagara Escarpment and situated in a UNESCO Biosphere Reserve. Seven incoming firstyear students and two upper-year student leaders participated in a five-day canoe trip in Algonquin Provincial Park, located north of Toronto, in the summer of 2010. In addition to a curriculum that included teaching the technical skills of canoeing and outdoor living, the two upper-year student facilitators also incorporated specific discussion topics that focused on the "ins-and-outs" of student life. In informal settings (e.g., around the campfire, when paddling, while hanging out at the campsite, etc.) the group engaged in conversations about networking with peers and professors, time management, study skills, the importance of work/school/life balance, and even where to buy the best pizza. Formal discussion topics included group dynamics/ leadership; undergraduate life; diversity and positive interpersonal relationships; living away from home; and health/well-being. The BaseCamp program was designed to build community, promote academic success, increase personal capacity (self-confidence and leadership) and promote an appreciation of the natural world.

All seven incoming students participated in a mixed methods, exploratory pilot study that entailed the administration of three surveys (pre-trip, posttrip and four months later) and participation in a post-trip focus group. The three survey instruments used in the study measured life effectiveness, sense of community and sense of place. These survey measures were selected because of their relevance to knowledge and behaviour that we believe might be linked to academic success and campus integration.

The Life Effectiveness literature examines the extent to which a person's actions, behaviour and feelings are effective in managing and succeeding in life (Neill, Marsh \& Richards, 2003). The Life Effectiveness Questionnaire (Neill et al., 2003) measured eight indicators of personal change, including time management, social competence, achievement/ motivation, intellectual flexibility, task leadership, emotional control, and active initiative as well as overall perceptions of life effectiveness. In addition, in order to explore the potential impact of this experience on the group's attitude toward one another and their sense of affiliation with the institution, measures of performance were selected from the Sense of Community and Sense of Place literature. The Brief Sense of Community Index (BSCI) measures feelings of belonging and mutual dependence within a group (Long \& Perkins, 2003), and The Sense of Place Questionnaire (Todd, Young, Anderson, O'Connell, \& Breunig, 2009) measures feelings of connection and attachment to a specific influential location (i.e., Algonquin Park). In addition to these quantitative 
measures, six of the seven students participated in a follow-up focus group session conducted four months post trip. Questions in the focus group, which was facilitated by the researchers (who also administer the BaseCamp program), were designed to further explore the impact of BaseCamp participation on the formation of peer-network social supports, level of integration into university life, and perceptions of academic success.

Results from the three quantitative measures indicated that the five-day outdoor orientation experience did significantly impact Life Effectiveness, Sense of Community, and Sense of Place indicators (see Table 1). The Life Effectiveness subscales of "time management," "task leadership," and "active initiative" significantly increased, as did the sense of community factors of "membership," "influence," and "shared emotional connection" - all of which increased during the trip and remained at high levels four months later. Social aspects of place were also found to change. Significantly, students reported that Algonquin Park provided them the opportunity to associate with special people in their lives, socialize with others, and that they had fond memories of time with others in that place. Students reported they still experienced heightened levels of these social impacts of place four months after the completion of the trip. However, it is important to note that results reported as statistically significant must be interpreted with caution due to the small sample size. This is a limitation of this exploratory pilot study.

The main themes that emerged from the focus group transcripts further reinforced these findings. Participants reported that they developed and continued to feel a strong sense of community with their peers and student leaders. They identified that these connections and enhanced social support networks helped them throughout the first term of their studies and they reported that helpful "tips" about campus life (e.g., importance of meeting professors, how to plan in advance for assignments) contributed to their academic success. As one student reflected:

Brock BaseCamp was an awesome
experience. Our leaders did a
fantastic job helping us understand
what first year was going to be like
and telling us about all the resources
available to us. I think being in an
"outdoor classroom" really helped us
have more fun and become friends a
lot faster than being part of a normal
orientation. (Jonathan, BaseCamp
participant)

Although many of these findings are congruent with the previous relevant literature (e.g., Austin, Martin, Mittelstaedt, Schanning, \& Ogle, 2009; Bell, 2006; Jones \& Hinton, 2007, Wolfe \& Kay, 2011), it is important to note that this pilot study is among the first, to our knowledge, that demonstrates the effectiveness of outdoor orientation programs within a Canadian context. Future research is needed to continue to track this initial cohort (and successive first-year cohorts) as they proceed throughout their university career. As Rummel, Acton, Costello, and Pielow (1999) recognize, academic success and social integration are key factors that students continually visit and revisit as they evaluate their life at school, and which either reaffirms (or disconfirms) their decision/choice to attend a particular university. Student retention is an ongoing process. When institutions of higher learning are able to convey a unique and meaningful sense of community, sense of place and space, students will feel that they belong - and will remain actively and successfully engaged. Outdoor orientation programs offer the potential to introduce prospective students to this type of engagement. As William commented after his Brock BaseCamp experience: "It's not just a building that you come to for class, it becomes a home." 


\section{TABLE 1}

Paired sample t-tests

\begin{tabular}{|c|c|c|c|c|c|c|}
\hline \multirow[t]{2}{*}{ Variable } & \multicolumn{2}{|c|}{ Pre-trip } & \multicolumn{2}{|c|}{ Post-trip } & \multirow[b]{2}{*}{$t$} & \multirow[b]{2}{*}{$p$} \\
\hline & $M$ & $S D$ & $M$ & $S D$ & & \\
\hline \multicolumn{7}{|l|}{ Life Effectiveness } \\
\hline Time management & 17.00 & 4.16 & 19.86 & 2.48 & $-2.41^{*}$ & .05 \\
\hline Social competence & 18.71 & 3.64 & 20.29 & 2.50 & -1.67 & .15 \\
\hline Achievement motivation & 20.57 & 3.05 & 21.57 & 2.37 & -1.08 & .32 \\
\hline Intellectual flexibility & 19.86 & 4.67 & 21.00 & 2.83 & -0.89 & .41 \\
\hline Task leadership & 17.14 & 2.80 & 19.29 & 2.69 & $-2.50^{*}$ & .05 \\
\hline Emotional control & 19.43 & 3.91 & 21.14 & 2.61 & -1.22 & .27 \\
\hline Active initiative & 20.00 & 3.32 & 22.29 & 2.43 & -1.64 & .15 \\
\hline Self confidence & 19.86 & 3.24 & 21.43 & 2.82 & $-3.67^{\star *}$ & .01 \\
\hline \multicolumn{7}{|l|}{ Sense of Community } \\
\hline Membership & 2.71 & 1.50 & 6.00 & 0.00 & $-5.81^{* * *}$ & .001 \\
\hline Influence & 5.67 & 1.03 & 6.50 & 1.05 & $-2.71^{*}$ & .04 \\
\hline Integration \& Fulfillment of Needs & 7.17 & 2.23 & 9.50 & 0.88 & -2.36 & .06 \\
\hline Shared Emotional Connections & 6.71 & 1.98 & 9.71 & 0.76 & $-3.97^{* *}$ & .01 \\
\hline \multicolumn{7}{|l|}{ Sense of Place } \\
\hline Trip location means a lot & 3.17 & 0.75 & 3.50 & 0.55 & -1.00 & .36 \\
\hline Trip location allows bonding with others & 2.83 & 0.98 & 3.83 & 0.41 & -2.24 & .08 \\
\hline $\begin{array}{l}\text { Trip location is the best place to do } \\
\text { activities I like to do }\end{array}$ & 2.86 & 0.69 & 3.29 & 0.76 & -2.12 & .08 \\
\hline $\begin{array}{l}\text { I get satisfaction out of the trip location } \\
\text { more than other places }\end{array}$ & 2.29 & 0.95 & 2.71 & 0.76 & -2.12 & .08 \\
\hline $\begin{array}{l}\text { I associate special people in my life with } \\
\text { the trip location }\end{array}$ & 2.43 & 0.79 & 3.43 & 0.79 & $-3.24^{*}$ & .02 \\
\hline $\begin{array}{l}\text { Being in the trip location is an important } \\
\text { part of my life }\end{array}$ & 2.86 & 0.69 & 3.29 & 0.49 & -2.12 & .08 \\
\hline $\begin{array}{l}\text { I would prefer to spend more time in the } \\
\text { trip location }\end{array}$ & 3.14 & 0.69 & 3.29 & 0.76 & -0.42 & .67 \\
\hline $\begin{array}{l}\text { Visiting the trip location allows me to } \\
\text { spend time with others }\end{array}$ & 3.14 & 0.38 & 3.71 & 0.49 & $-2.83^{*}$ & .03 \\
\hline $\begin{array}{l}\text { I have fond memories of past } \\
\text { experiences with others in the trip } \\
\text { location }\end{array}$ & 2.43 & 1.27 & 3.43 & 0.79 & $-2.65^{*}$ & .04 \\
\hline
\end{tabular}

Note. ${ }^{*} p<.05 .{ }^{* *} p \leq .01 .{ }^{* * *} p \leq .001$ 


\section{References}

Austin, M., Martin, B., Mittelstaedt, R., Schanning, K., \& Ogle, D. (2009). Outdoor orientation program effects: Sense of place and social benefits. Journal of Experiential Education, 31(3), 435-439.

Barefoot, B. \& Koch, D. (2011). Preliminary findings from a national survey of efforts to improve undergraduate studentsuccess and retention, Gardner Institute for Excellence in Undergraduate Education. Paper presented at the $31^{\text {st }}$ Annual First-Year Experience Conference, Atlanta, Georgia.

Bell, B. (2006). Wilderness orientation: Exploring the relationship between college pre-orientation programs and social support. Journal of Experiential Education, 29(2), 145-167.

Davis-Berman, J. \& Berman, D. (1996). Using the wilderness to facilitate adjustment to college: an updated description of wilderness orientation programs. Journal of Experiential Education, 19(1), 22-28.

Finnie, R. \& T. Qiu. (2009). Moving through, moving on: Persistence in postsecondary education in Atlantic Canada, evidence from the PSIS. Statistics Canada. Culture Tourism and the Centre for Education Statistics - Research Papers, Catalogue no. 81-595-M - No. 072.

Gass, M.A., Garvey, D.E., \& Sugarman, D.A. (2003). The long-term effects of a first-year student wilderness orientation program. Journal of Experiential Education, 26(1), 34-40.

Hollins, T.N. (2009). Examining the impact of a comprehensive approach to student orientation. Inquiry, 14(1), 15-27.

Jones, J. \& Hinton, J. (2007). Study of self-efficacy in a freshman wilderness experience program: Measuring general versus specific gains. Journal of Experiential Education, 29(3), 382-385.
Lamothe, D., Currie, F., Alisat, S., Sullivan, T., Pratt, M., Pancer, S., \& Humsberger, B. (1995). Impact of a social support intervention on the transition to university. Canadian Journal of Community Mental Health, 14, 167-180.

Long, D.A. \& Perkins, D.D. (2003). Confirmatory factor analysis of the Sense of Community Index and development of a Brief SCI. Journal of Community Psychology, 31(3), 279-296.

Neill, J.T., Marsh, H.W., \& Richards, G.E. (2003). The life effectiveness questionnaire: Development and psychometrics. Unpublished manuscript, University of Western Sydney, Sydney, NSW, Australia.

Oldmixon, M. (2007). The great outdoors: Campus and individual benefits of outdoor adventure programming. The Bulletin of the Association of College Unions International, 75(2), 382-385.

Rae, B. (2005). Ontario: A leader in learning. Retrieved from www.tcu.gov.on.ca/eng/ document /reports/postsec.pdf

Rummel, A., Acton, D., Costello, S., \& Pielow, G. (1999). Is all retention good? An empirical study. College Student Journal, 33(2), 241-245.

Tinto, V. (1997). Classrooms as communities: Exploring the educational character of student persistence. Journal of Higher Education, 68(6), 599-623.

Todd, S.L., Young, A.B., Anderson, L.S., O’Connell, T.S., \& Breunig, M. (2009). Sense of place in outdoor pursuits trip groups. In D. B. Klenosky \& C. LeBlanc Fisher (Eds.), Proceedings of the 2008 Northeastern Recreation Research Symposium (pp. 172-180). Newtown Square, PA: U.S. Department of Agriculture, Forest Service, Northern Research Station.

Wolfe, B.D. \& Kay, G. (2011). Perceived impact of an outdoor orientation program for firstyear university students. Journal of Experiential Education, 34(1), 19-34. 


\section{Biographies}

Anna H. Lathrop is Associate Dean for Undergraduate Studies, Faculty of Applied Health Sciences, Brock University, St. Catharines, Ontario. E-mail: anna. lathrop@brocku.ca

Timothy S. O'Connell is an Associate Professor of Recreation and Leisure Studies, Brock University. E-mail: tim.oconnell@brocku.ca

Ryan A. Howard is a Doctoral Student in Applied Health Sciences (Social and Cultural Health Studies), Brock University. E-mail: ryan.howard@brocku.ca

Anna, Tim and Ryan are the founders and administrative team for Brock BaseCamp. 